\title{
PENGARUH DIMENSI SERVICE QUALITY (TANGIBLE, RELIABILITY, ASSURANCE, RESPONSIVENESS DAN EMPHATY) PADA CUSTOMER SERVICE BANK BCA KCU DARMO SURABAYA TERHADAP PERSEPSI NASABAH
}

Yosinta Ayuwandani

Henrycus Winarto

Bambang Budiarto

Fakultas Bisnis dan Ekonomika, Universitas Surabaya

Jl. Mejoyo II No. 13, Kali Rungkut, Kec. Rungkut, Kota Surabaya, Jawa Timur 60293

\begin{abstract}
ABSTRAK
Penelitian ini membahas tentang Pengaruh Dimensi Service Quality (Tangible, Reliability, Assurance, Responsiveness dan Emphaty) Pada Customer Service Bank BCA KCU Darmo Surabaya Terhadap Persepsi Nasabah Tahun 2019. Adakah pengaruh dimensi SERVQUAL pada Customer Service bank BCA KCU Darmo Surabaya terhadap persepsi nasabah. Data yang digunakan dalam penelitian ini diperoleh dari hasil kuesioner yang telah dibagikan kepada nasabah bank BCA KCU Darmo Surabaya. Metode yang digunakan dalam penelitian ini adalah metode kuantitatif. Probability sampling adalah teknik pengambilan sampel yang memberikan peluang yang sama bagi setiap unsur (anggota) populasi untuk dipilih menjadi sampel dalam penelitian ini. Jenis probability sampling yang digunakan dalam pengambilan sampel pada penelitian ini adalah simple random sampling. Karena didalam penelitian ini tidak membedakan gender, ras, status sosial, pekerjaan dan lain sebagainya. Variabel yang digunakan dalam penelitian ini adalah persepsi nasabah sebagai variabel dependen (Y) dan Service Quality sebagai variabel independen (X). Kemudian, dimensi SERVQUAL yang terdiri dari (tangibles) (X1), (reliability) (X2), (assurance) (X3), (responsiveness) (X4), dan (emphaty) (X5). Hasil dari penelitian ini diperoleh bahwa dimensi SERVQUAL yang terdiri dari Tangible, Reliability, Assurance, Responsiveness dan Emphaty pada Customer Service bank BCA KCU Darmo Surabaya mempunyai pengaruh yang signifikan terhadap persepsi nasabah. Dan faktor yang paling dominan adalah variabel emphaty.

Kata Kunci: Dimensi Service Quality (tangible, reliability, assurance, responsiveness dan emphaty), Customer Service, Persepsi Nasabah
\end{abstract}

\begin{abstract}
This study discusses the influence of Service Quality Dimensions in Customer Service of Bank BCA KCU Darmo Surabaya on the Perception of Customer in 2019. The data used in this study was obtained from the results of a questionnaire that had been distributed to BCA KCU Darmo Surabaya customers. The method used in this research is quantitative method. Probability sampling is a sampling technique that provides equal opportunities for each element (member) of the population to be selected as a sample in this study. The type of probability sampling used in sampling in this study is simple random sampling. The results of this study were obtained that the SERVQUAL dimension consisting of Tangible, Reliability, Assurance, Responsiveness and Emphaty on BCA Customer Service Bank Darmo Surabaya has a significant influence on customer perceptions. And the most dominant factor is the empathy variable.
\end{abstract}

Keywords: Service Quality Dimensions, Customer Service, Customer Perception

\section{PENDAHULUAN}

Kualitas pelayanan merupakan faktor penting dalam menentukan keberhasilan usaha khususnya untuk perusahaan yang bergerak pada bidang perbankan, hal ini didasari atas azas kepercayaan yang harus diciptakan oleh setiap bank bersaing untuk menarik minat nasabah agar menggunakan produk perusahaannya. Kualitas pelayanan adalah segala bentuk aktivitas yang dilakukan oleh perusahaan untuk mencapai keinginan dan harapan konsumen (Harish, 2014). Kualitas pelayanan yang baik akan menimbulkan kepuasan dan loyalitas para nasabah bank tertentu serta dapat memenuhi kebutuhan nasabah, menarik nasabah baru, sehingga nantinya dapat meningkatkan jumlah pengguna jasa perbankan tersebut.

Parasuraman, Berry dan Zeithaml (1985) memperkenalkan model SERVQUAL (Service Quality), yang berbicara tentang kualitas layanan sebagai kesenjangan antara tingkat layanan yang diharapkan dengan tingkat persepsi konsumen dari layanan yang diterima (Parasuraman. 2001). Model pengukuran SERVQUAL ini dikenal dengan 5 dimensi: realibility (keandalan), responsiveness (daya tanggap), assurance (jaminan), empathy (empati), dan tangible (bukti fisik), untuk menilai persepsi kualitas layanan konsumen dalam organisasi jasa dan ritel (Putri Dwi Cahyani, 2016). 
Pentingnya persepsi nasabah terhadap kualitas pelayanan yang diberikan oleh perbankan dipahami benar oleh PT. Bank Central Asia (BCA) sebagai salah satu bank swasta yang sangat besar dan terkemuka di Indonesia sehingga saat ini Bank BCA baru saja mendapatkan penghargaan Bank terbaik di Indonesia dan Asia. Sebagai bentuk pelayanan kepada nasabah, Bank BCA mengoptimalkan kinerja Customer Service untuk melayani transaksi, menyelesaikan dan memberi solusi terhadap keluhan yang dialami oleh nasabahnya. Customer Service dituntut untuk melayani transaksi para nasabah dengan cepat dan teliti, hal ini dikarenakan setiap nasabah pasti mempunyai kepentingan transaksi yang berbeda-beda.

\section{METODE PENELITIAN}

Metode yang digunakan dalam penelitian ini adalah metode kuantitatif. Data yang digunakan hanya data primer. Data tersebut diperoleh dari pengumpulan hasil wawancara serta jawaban dari nasabah BANK BCA KCU Darmo Surabaya atas pengisian kuesioner yang telah dibagikan dan telah diolah. Penelitian ini menggunakan jumlah sampel sebanyak 100 responden. Jenis probability sampling yang digunakan dalam pengambilan sampel pada penelitian ini adalah simple random sampling.

Teknik Analisis Data penelitian ini menggunakan analisis deskriptif, uji kualitas data, dan uji asumsi klasik. Model Analisa Data yang digunakan adalah analisis regresi linear berganda dan uji koefisiensi determinasi. Penelitian ini menggunakan pengujian hipotesis uji statistik F dan uji T (parsial). Dengan menggunakan metode penelitian ini diharapkan mendapat data dan hasil yang akurat untuk menganalisis Pengaruh Dimensi Service Quality (Tangible, Reliability, Assurance, Responsiveness dan Emphaty) Pada Customer Service Bank BCA KCU Darmo Surabaya Terhadap Persepsi Nasabah Tahun 2019.

\section{HASIL DAN PEMBAHASAN}

Menurut Pride \& Ferrel dalam Latumaerissa. (2013:45) persepsi adalah proses pemilihan, pengorganisasian dan penginterprestasian masukan informasi, sensasi yang diterima melalui penglihatan, perasa, pendengaran, penciuman dan sentuhan untuk menghasilkan makna. Pada tabel 1 dapat menjelaskan presepsi nasabah Bank BCA setelah melakukan transaksi langsung di BANK BCA KCU Darmo Surabaya.

Tabel 1. Presepsi Nasabah

Persepsi Nasabah

\begin{tabular}{|c|c|c|c|}
\hline $\mathbf{P 1}$ & $\begin{array}{l}\text { Merasakan kenyamanan pada saat bertansaksi di BCA KCU Darmo } \\
\text { Surabaya }\end{array}$ & Frekuensi & $\begin{array}{l}\text { Persentase } \\
(\%)\end{array}$ \\
\hline 5 & Sangat Setuju (SS) & 49 & 44,5 \\
\hline 4 & Setuju (S) & 35 & 31,8 \\
\hline 3 & Netral $(\mathrm{N})$ & 26 & 23,6 \\
\hline 2 & Tidak Setuju (TS) & - & - \\
\hline 1 & Sangat Tidak Setuju (STS) & - & - \\
\hline \multicolumn{2}{|r|}{ Jumlah } & 110 & 100 \\
\hline $\mathbf{P 2}$ & $\begin{array}{l}\text { Selalu disambut dengan baik dan ramah dengan staf dan Costumer } \\
\text { Service pada saat berkunjung ke BCA KCU Darmo Surabaya }\end{array}$ & Frekuensi & $\begin{array}{c}\text { Persentase } \\
(\%)\end{array}$ \\
\hline 5 & Sangat Setuju (SS) & 39 & 35,5 \\
\hline 4 & Setuju (S) & 47 & 42,7 \\
\hline 3 & Netral $(\mathrm{N})$ & 24 & 21,8 \\
\hline 2 & Tidak Setuju (TS) & - & - \\
\hline 1 & Sangat Tidak Setuju (STS) & - & - \\
\hline \multicolumn{2}{|r|}{ Jumlah } & 110 & 100 \\
\hline $\mathbf{P 3}$ & $\begin{array}{l}\text { Costumer Service selalu melaksanakan tugasnya dengan cepat dan } \\
\text { teliti }\end{array}$ & Frekuensi & $\begin{array}{l}\text { Persentase } \\
(\%)\end{array}$ \\
\hline 5 & Sangat Setuju (SS) & 39 & 35,5 \\
\hline 4 & Setuju (S) & 36 & 32,7 \\
\hline 3 & Netral (N) & 35 & 31,8 \\
\hline 2 & Tidak Setuju (TS) & - & - \\
\hline 1 & Sangat Tidak Setuju (STS) & - & - \\
\hline \multicolumn{2}{|r|}{ Jumlah } & 110 & 100 \\
\hline
\end{tabular}




\begin{tabular}{|c|c|c|c|}
\hline $\mathbf{P 4}$ & $\begin{array}{l}\text { Costumer service selalu meminta maaf apabila membuat nasabah } \\
\text { menunggu lama }\end{array}$ & Frekuensi & $\begin{array}{l}\text { Persentase } \\
(\%)\end{array}$ \\
\hline 5 & Sangat Setuju (SS) & 40 & 36,4 \\
\hline 4 & Setuju (S) & 40 & 36,4 \\
\hline 3 & Netral (N) & 30 & 27,3 \\
\hline 2 & Tidak Setuju (TS) & - & - \\
\hline \multirow[t]{2}{*}{1} & Sangat Tidak Setuju (STS) & - & - \\
\hline & Jumlah & 110 & 100 \\
\hline P5 & $\begin{array}{l}\text { Costumer service sangat membantu dalam menangani setiap } \\
\text { pertanyaan para nasabahnya }\end{array}$ & Frekuensi & $\begin{array}{l}\text { Persentase } \\
(\%)\end{array}$ \\
\hline 5 & Sangat Setuju (SS) & 40 & 36,4 \\
\hline 4 & Setuju (S) & 36 & 32,7 \\
\hline 3 & Netral (N) & 34 & 30,9 \\
\hline 2 & Tidak Setuju (TS) & - & - \\
\hline \multirow[t]{2}{*}{1} & Sangat Tidak Setuju (STS) & - & - \\
\hline & Jumlah & 110 & 100 \\
\hline P6 & Costumer Service selalu sabar dalam melayani para nasabahnya & Frekuensi & $\begin{array}{l}\text { Persentase } \\
(\%)\end{array}$ \\
\hline 5 & Sangat Setuju (SS) & 49 & 44,5 \\
\hline 4 & Setuju (S) & 34 & 30,9 \\
\hline 3 & Netral $(\mathrm{N})$ & 27 & 24,5 \\
\hline 2 & Tidak Setuju (TS) & - & - \\
\hline \multirow[t]{2}{*}{1} & Sangat Tidak Setuju (STS) & - & - \\
\hline & Jumlah & 110 & 100 \\
\hline $\mathbf{P 7}$ & $\begin{array}{l}\text { Costumer Service selalu menyambut dengan senyuman, salam dan } \\
\text { sapa kepada para nasabahnya }\end{array}$ & Frekuensi & $\begin{array}{c}\text { Persentase } \\
(\%)\end{array}$ \\
\hline 5 & Sangat Setuju (SS) & 51 & 46,4 \\
\hline 4 & Setuju (S) & 36 & 32,7 \\
\hline 3 & Netral $(\mathrm{N})$ & 23 & 20,9 \\
\hline 2 & Tidak Setuju (TS) & - & - \\
\hline 1 & Sangat Tidak Setuju (STS) & - & - \\
\hline & Jumlah & 110 & 100 \\
\hline
\end{tabular}

Sumber: Data Primer diolah penulis, 2019

Persepsi Nasabah terhadap dimensi SERVQUAL pada Customer Service bank BCA KCU Darmo Surabaya adalah sebagai berikut :

1. Merasakan kenyamanan pada saat bertransaksi di BCA KCU Darmo Surabaya. Para nasabah bank BCA KCU Darmo Surabaya merasa nyaman pada saat melakukan transaksi di bank tersebut, karena ruangan yang ada di bank BCA KCU Darmo Surabaya sangat bersih dan suasananya sangat nyaman, sehingga membuat para nasabah senang berada di dalam ruangan tersebut pada saat melakukan transaksi. Kenyamanan para nasabah bukan hanya dirasakan pada ruangan yang bersih dan indah, tetapi para staf didalam ruangan tersebut juga selalu menyambut para nasabah dengan sangat ramah dan sopan. Terutama para petugas keamanan yang sedang berjaga di dalam ruangan tersebut selalu membantu para nasabah sebelum mereka melakukan transaksi. Para nasabah bank BCA kcu Darmo sendiri merasa sangat terbantu dengan kehadiran petugas keamanan tersebut, karena selain mereka membantu menjaga keamanan serta ketertiban didalam ruangan, mereka juga sangat membantu nasabah sebelum mereka memulai bertransaksi.

2. Para nasabah bank BCA KCU darmo pun selalu disambut dengan baik dan ramah oleh para staf di dalam ruangan tersebut. Tidak hanya petugas keamanan yang berjaga di dalam saja, akan tetapi teller dan Customer Service pun selalu menyambut para nasabahnya dengan senang hati. Dan para staf yang bertugas di dalam ruangan tersebut selalu menyambut para nasabahnya dengan senyum dan sapa. Sehingga para nasabah bank BCA KCU Darmo pun selalu merasa senang apabila mereka disambut para staf didalam ruangan tersebut dengan ramah dan sopan.

3. Menurut para nasabah pada saat mereka melakukan transaksi di bank BCA KCU Darmo, Customer Service selalu melaksanakan tugasnya dengan cepat dan teliti. Mereka selalu membantu para nasabahnya pada saat bertransaksi. Karena dalam satu hari, Customer Service tidak hanya melayani satu, atau dua nasabah saja. Mereka bisa melayani banyak nasabah dengan berbagai macam 
kepentingan transaksi. Menurut para nasabah yang melakukan transaksi dengan customer service, mereka berpendapat bahwa Customer Service di bank BCA KCU darmo tersebut telah melaksanakan tugasnya dengan baik. Customer Service juga melaksanakan tugas tersebut dengan cepat dan teliti agar tidak terjadi kesalahan pada saat melayani para nasabahnya. Customer service sendiri tidak hanya di tuntut untuk melakukan tugasnya dengan cepat, tetapi mereka juga di tuntut untuk melakukan tugasnya dengan teliti. Karena, kesalahan pencatatan pada saat transaksi bisa berakibat fatal bagi perusahaan serta bagi nasabahnya.

4. Customer service selalu meminta maaf apabila telah membuat nasabahnya menunggu terlalu lama. Didalam etika perusahaan bank BCA KCU Darmo Surabaya selalu menerapkan hal tersebut setiap kali stafnya akan melayani transaksi para nasabahnya. Karena di setiap transaksi para nasabah, pasti mempunyai kepentingan yang berbeda-beda. Jika sekiranya transaksi nasabah tersebut membutuhkan waktu yang lama, tentu para nasabah yang lain harus menunggu sampai nasabah yang sedang dilayani tersebut benar-benar menyelesaikan kepentingan transaksinya. Dari jawaban nasabah yang berbeda tersebut dapat diambil dua kesimpulan, yaitu yang pertama nasabah tersebut pernah mengalami kejadian tersebut sehingga mereka menjawab sangat setuju/setuju.

Persepsi muncul setelah mereka melihat langsung dan menganalisis sikap dan perilaku seseorang pada saat mereka berinteraksi dengan orang lain. Setelah itu, mereka bisa menilai bagaimana sikap seseorang tersebut terhadap orang lain. Begitu pula dengan persepsi nasabah akan muncul saat mereka melihat langsung dan menganalisis sikap serta perilaku yang diberikan oleh Customer Service terhadap para nasabahnya. Selanjutnya, mereka menilai dan kemudian muncul persepsi terhadap Customer Service tersebut. Apakah pelayanan yang diberikan sudah memuaskan atau masih kurang memuaskan bagi para nasabahnya. Dan kemudian nasabah akan merespon melalui tindakan. Jika hanya sedikit nasabah yang komplain terhadap pelayanan suatu bank, maka dapat dikatakan bahwa kualitas pelayanan di bank tersebut sudah baik dan memenuhi ekspektasi nasabah. Begitu pula sebaliknya, apabila bank tersebut menerima banyak komplain dari para nasabahnya, maka kualitas pelayanan yang diberikan bank tersebut masih belum memuaskan dan belum memenuhi ekpektasi nasabah.

Menurut para nasabah bank BCA KCU darmo Surabaya, Customer Service juga sangat membantu dalam menangani setiap pertanyaan para nasabahnya. Seorang Customer Service tidak hanya dituntut untuk selalu bekerja cepat dan teliti, tetapi mereka juga di tuntut untuk bisa menangani setiap keluhan dari para nasabahnya dan menjelaskannya sedetail mungkin kepada nasabah tersebut. Oleh sebab itu, Customer Service harus mengetahui tentang keseluruhan produk-produk yang di berikan oleh bank BCA KCU Darmo kepada para nasabahnya. Agar ketika sewaktu-waktu terdapat nasabah yang melapor dan melaporkan tentang salah satu produk yang sedang trouble atau mendapati masalah lainnya, Customer Service bisa segera mengatasi dan membantu menyelesaikan kendala yang sedang dihadapi nasabah tersebut.

Sebagai seorang Customer Service, mereka juga diwajibkan untuk mempunyai kesabaran lebih pada saat melayani transaksi para nasabahnya. Mereka juga di tuntut untuk telaten dalam mengarahkan para nasabahnya pada saat proses transaksi berlangsung. Ketika nasabah mengalami kendala, Customer Service harus dengan sigap membantu nasabahnya tersebut. Mereka harus menjelaskan kepada nasabahnya secara mendetail dan secara bertahap. Customer Service di bank BCA KCU Darmo dengan sabar menjelaskan detail dari transaksi para nasabah-nasabahnya.

Customer Service di bank BCA KCU Darmo Surabaya juga selalu menyambut para nasabahnya dengan senyum, salam dan sapa. Hal tersebut tidak hanya berlaku untuk customer service saja, tetapi juga untuk staf-staf yang lainnya seperti teller dan security yang ada didalam ruangan tersebut. Para nasabah mengaku senang apabila disambut dengan sangat ramah oleh para staf di bank BCA KCU Darmo tersebut. Mereka berpendapat bahwa dengan adanya perlakuan seperti itu kepada nasabah, akan memunculkan persepsi yang baik dari para nasabahnya. Karena mereka merasa sangat dihargai dan dihormati sebagai nasabah di bank tersebut.

Dalam penelitian ini, uji t digunakan untuk mengetahui apakah variabel independen secara parsial berpengaruh terhadap variabel dependen. Hasil uji pengaruh Service Quality Tangible, Reliability, Assurance, Responsiveness dan Emphaty pada Customer Service terhadap persepsi nasabah adalah sebagai berikut: 
Tabel 2 Hasil Uji T

\section{Coefficients $^{a}$}

\begin{tabular}{|c|c|c|c|c|c|c|}
\hline & \multirow{2}{*}{ Model } & \multicolumn{2}{|c|}{$\begin{array}{c}\text { Unstandardized } \\
\text { Coefficients }\end{array}$} & \multirow{2}{*}{$\begin{array}{r}\text { Standardized } \\
\text { Coefficients }\end{array}$} & \multirow{2}{*}{$\mathrm{t}$} & \multirow{2}{*}{ Sig. } \\
\hline & & $B$ & Std. Error & & & \\
\hline \multirow{6}{*}{1} & (Constant) & 4,490 & 1,286 & & 3,491 & 0,001 \\
\hline & $\mathrm{X} 1$ & $-0,748$ & 0,327 & $-0,322$ & $-2,287$ & 0,124 \\
\hline & $\mathrm{X} 2$ & 0,242 & 0,274 & 0,105 & 1,883 & 0,004 \\
\hline & X3 & 0,410 & 0,325 & 0,179 & 1,961 & 0,010 \\
\hline & $\mathrm{X} 4$ & $-0,426$ & 0,382 & $-0,180$ & $-1,114$ & 0,108 \\
\hline & $\mathrm{X} 5$ & 2,229 & 0,277 & 0,955 & 8,054 & 0,000 \\
\hline
\end{tabular}

Sumber: Data Primer diolah penulis, 2019

Dari hasil uji $\mathrm{t}$, diperoleh nilai $\mathrm{t}_{\text {tabel }}$ sebesar 1,65964 ( $\left.\mathrm{df}=110-5-1=104\right)$. Di dalam uji $\mathrm{t}$ ini akan melakukan perbandingan nilai $t_{\text {hitung }}$ dengan nilai tabel pada tingkat signifikansi 0,05 . Berdasarkan hasil uji t pada tabel 4.24 maka dapat disimpulkan hipotesis uji t adalah sebagai berikut:

1. Service Quality Tangible $\left(\mathrm{X}_{1}\right)$ memiliki thitung sebesar $-2,287 \leq 1,65964$ dan nilai signifikansi sebesar $0,124 \geq 0,05$, maka $\mathrm{H}_{0}$ diterima dan $\mathrm{H}_{1}$ ditolak. Sehingga dapat disimpulkan bawah Service Quality Tangible pada Customer Service bank BCA Darmo Surabaya tidak berpengaruh signifikan terhadap persepsi nasabah.

2. Service Quality Reliability $\left(\mathrm{X}_{2}\right)$ memiliki thitung sebesar $1,883 \geq 1,65964$ dan nilai signifikansi sebesar $0,004 \leq 0,05$, maka $\mathrm{H}_{0}$ ditolak dan $\mathrm{H}_{2}$ diterima. Sehingga dapat disimpulkan bawah Service Quality Reliability pada Customer Service bank BCA Darmo Surabaya berpengaruh positif signifikan terhadap persepsi nasabah.

3. Service Quality Assurance $\left(\mathrm{X}_{3}\right)$ memiliki thitung sebesar $1,961 \geq 1,65964$ dan nilai signifikansi sebesar $0,010 \leq 0,05$, maka $\mathrm{H}_{0}$ ditolak dan $\mathrm{H}_{3}$ diterima. Sehingga dapat disimpulkan bawah Service Quality Assurance pada Customer Service bank BCA Darmo Surabaya berpengaruh positif signifikan terhadap persepsi nasabah.

4. Service Quality Responsiveness $\left(\mathrm{X}_{4}\right)$ memiliki thitung sebesar $-1,114 \leq 1,65964$ dan nilai signifikansi sebesar $0,108 \leq 0,05$, maka $\mathrm{H}_{0}$ diterima dan $\mathrm{H}_{4}$ ditolak. Sehingga dapat disimpulkan bawah Service Quality Responsiveness pada Customer Service bank BCA Darmo Surabaya tidak berpengaruh signifikan terhadap persepsi nasabah.

5. Service Quality Emphaty (x5) memiliki thitung sebesar 8,054 $\geq 1,65964$ dan nilai signifikansi sebesar $0,000 \leq 0,05$, maka $\mathrm{H}_{0}$ ditolak dan $\mathrm{H}_{5}$ diterima. Sehingga dapat disimpulkan bawah Service Quality Emphaty pada Customer Service bank BCA Darmo Surabaya berpengaruh positif signifikan terhadap persepsi nasabah.

Tabel 3. Hasil Uji F

\begin{tabular}{ccccccc}
\hline \multicolumn{8}{c}{ ANOVA $^{a}$} \\
\hline \multicolumn{1}{c}{ Model } & Sum of & $d f$ & Mean Square & $F$ & Sig. \\
& Squares & & & & \\
\hline 1 & Regression & 1854,018 & 5 & 370,804 & 30,702 & $0,000^{\mathrm{b}}$ \\
& Residual & 1256,073 & 104 & 12,078 & & \\
& Total & 3110,090 & 109 & & & \\
& &
\end{tabular}

Sumber: Data Primer diolah penulis, 2019

Tujuan pengujian uji $\mathrm{f}$ adalah untuk mengetahui apakah variable independen yang digunakan dalam penelitian berpengaruh secara simultan terhadap variabel dependen dengan membandingkan nilai $\mathrm{F}_{\text {hitung }}$ dengan $\mathrm{F}_{\text {tabel }}$ dan menggunakan signifikansi sebesar $5 \%$ atau 0,05 . Berdasarkan tabel 4.26

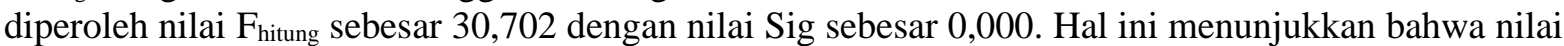
Fhitung lebih besar dari Ftabel 2,46 (df1 = k-1, df2=n-k) $\mathrm{k}$ adalah jumlah variabel, dan $\mathrm{n}$ adalah jumlah responden.

Hasil dari uji f tersebut memiliki nilai Sig lebih kecil dari 0,05. Dengan demikian $\mathrm{H}_{0}$ ditolak dan $\mathrm{H}_{\mathrm{a}}$ diterima. Artinya service quality tangible, reliability, assurance, responsiveness dan emphaty 
pada customer service bank BCA KCU Darmo Surabaya mempunyai pengaruh secara simultan dan berpengaruh signifikan terhadap persepsi nasabah.

\section{KESIMPULAN}

Secara parsial menggunakan uji t, Service Quality Reliability, Assurance, dan Emphaty pada Customer Service bank BCA Darmo Surabaya berpengaruh positif signifikan terhadap persepsi nasabah sedangkan Service Quality Tangible dan Responsiveness pada Customer Service bank BCA Darmo Surabaya tidak berpengaruh signifikan terhadap persepsi nasabah.

Hasil dari uji f menunjukan bahwa Service Quality Tangible, Reliability, Assurance, Responsiveness dan Emphaty pada Customer Service bank BCA KCU Darmo Surabaya mempunyai pengaruh secara simultan dan berpengaruh signifikan terhadap persepsi nasabah.

\section{DAFTAR PUSTAKA}

A, Parasuraman. 2001. The Behaviorial Consequenses of Service Quality, Jurnal of Marketing. Vol 60. Berry, Parasuraman dan Zeithaml, V.A. (1985). Conceptual Model of Service Quality and its implication for future research. Jurnal Marketing, Vol 49. 41-50.

Harish M.Azka, Novirani Dwi dan Adianti Hari. 2014. Usulan Perbaikan Kualitas Pelayanan Menggunakan Dimensi Banking Service Quality dengan Metode Service Quality (Studi Kasus di Bank X. Jurnal Online Institut Teknologi Nasional, Vol 2.

Julius R. Latumaerissa. (2013). Bank dan Lembaga Keuangan Lain. Jakarta : Salemba Empat.

Putri Dwi Cahyani. 2016. Tingkat Kepuasan Nasabah terhadap Kualitas Layanan Perbankan Syariah di Yogyakarta. Jurnal Bisnis dan Manajemen. Vol 6, No 2. 